\title{
Inequalities in the provision of sexual health information for young people
}

\author{
Marian McLaughlin, Kate Thompson, Kader Parahoo, Janice Armstrong, Allison Hume
}

\begin{abstract}
Background Sexual health has been emphasised in national and regional strategies as a target for health and social well-being. In Northern Ireland ( $\mathrm{NI})$, the Sexual Health Promotion Strategy concentrates on reducing the incidence of sexually transmitted infections (STIs), reducing the number of unplanned births to teenage mothers, providing appropriate, effective and equitable sexual health information, and facilitating access to sexual health services. This article reports on a study carried out within $\mathrm{NI}$ and explores young people's knowledge and sources of sexual health information.
\end{abstract}

Methods School pupils aged $14-18$ years $(n=414)$ participated in the study and a self-administered questionnaire was used to collect the data.

Results Whilst approximately half of the respondents reported being sexually active, only $68.2 \%$ always used some form of contraception. In fact, $40.8 \%$ of sexually active females had used the 'morning-after pill', with
$37.5 \%$ of these respondents using this method more than once. The results also indicated that students receive varying amounts of sexual health information from schools resulting in inequalities with regard to sources of information. Students from a Roman Catholic religious background were more likely to receive information on sexual health from informal sources such as friends, books/magazines or television/radio than from within the school environment compared with their Protestant counterparts.

Conclusions The provision of standard and accurate information appropriate to the target population is necessary in order to reduce the increasing rates of STIs and help the Government reach their target of halving the teenage pregnancy rate by the year 2010 .

Keywords emergency contraception, health services, sexual health, sex education, young people

J Fam Plann Reprod Health Care 2007; 33(2): 99-105

(Accepted 20 March 2006)

\section{Introduction}

Recent studies from The United Nations Children's Fund (UNICEF) ${ }^{1}$ demonstrate that countries with lower rates of teenage pregnancy and sexually transmitted infections (STIs) provide good sex and relationships education, easy access to sexual health services and a social climate that does not discourage sexual activity amongst young people. In comparison to other European countries the sexual health of young people living in Britain is poor. ${ }^{2}$ British culture does not encourage open discussions about sex but instead "shows a marked ambivalence to teenage sexuality and young people receive very mixed messages about sex". 3

Social and cultural differences exist between Northern Ireland (NI) and the rest of the UK that impact on sexual health policies. For example, in NI the legal age of consent for females is 17 years, 1 year older than in the rest of the UK. In addition, the UK Abortion Act (1967) does not currently extend to NI. The education system in NI is also different from the rest of the UK and has a relatively complex structure. Whilst most secondary schools in

Institute of Nursing Research and School of Nursing, University of Ulster, Coleraine, Northern Ireland, UK

Marian McLaughlin, BSc, Research Assistant

Kate Thompson, MSc, Research Officer

Kader Parahoo, RMN, PhD, Professor in Nursing and Health Research, Director

Homefirst Community Trust, Spruce House, Ballymena, Northern Ireland, UK

Janice Armstrong, RGN, MSc, Senior Health Promotion Officer (Sexual Health)

Causeway Health and Social Services Trust, Coleraine Community Clinics, Coleraine, Northern Ireland, UK Allison Hume, RGN, BSc, Senior Nurse Manager

Correspondence to: Kate Thompson, Institute of Nursing Research and School of Nursing, University of Ulster, Cromore Road, Coleraine BT52 1SA, Northern Ireland. E-mail:Ka.Thompson@ulster.ac.uk
Key message points

- Young people obtaining emergency contraception should be encouraged to seek advice from their general practitioner or local family planning clinic to discuss future contraception needs.

- Provision of sexual health information through the education system should be standardised, accurate and appropriate.

- Formal peer group education should be considered as a method of providing sexual health information.

England and Wales are comprehensive, accepting pupils without regard to academic ability, NI operates a largely selective system for post-primary education (i.e. pupils aged over 11 years) with those of higher academic ability more likely to attend grammar schools. ${ }^{4}$

Schools in NI have a strong Christian ethos and up until recently no standardised curriculum existed for sex education. The guidance provided by the Department of Education for Northern Ireland prior to 2001 stated that school policies on sex education should be endorsed by the board of governors and communicated to parents. This inevitably led to an inequality with regard to the provision of sex education in NI. ${ }^{5}$ In 2001, the Northern Ireland Council for the Curriculum, Examinations and Assessment ${ }^{6}$ published new guidelines on relationships and sexuality education (RSE) to further assist schools in providing a programme of RSE that is appropriate to the needs and maturity of the pupils. The aims of RSE are to:

- "enhance the personal development, self-esteem and well-being of the young person;

- help a young person develop healthy and respectful friendships and relationships;

- foster an understanding of, and a healthy attitude to, human sexuality and relationships in a moral, social and spiritual framework;

- promote responsible behaviour and the ability to make informed decisions;

- help a young person come to value family life and marriage; 
- appreciate the responsibilities of parenthood;

- promote an appreciation of the value of human life and the wonder of birth." 5

Confusion and misinformation about sex can lead to mistakes and this is believed to be reflected in the high rate of unintended pregnancies and increased transmission of STIs amongst young people living in Britain. ${ }^{3}$ Despite a recent drop in the teenage pregnancy figures amongst those aged under 17 years, NI still has one of the highest teenage pregnancy rates in Europe with 1483 live births to young people under 20 years of age (3.7\% of the population). ${ }^{7}$ Furthermore, the number of new STIs in NI has almost doubled in the last decade. In 2003, the number of STIs increased by $4 \%$ with rates soaring amongst 16-24-yearolds. ${ }^{8}$

Teenage sexual health is a complex issue and an area, which until fairly recently, was under-investigated in NI. Recent research conducted including the Health and Social Wellbeing Survey ${ }^{9}$ and the Towards Better Sexual Health Survey ${ }^{5}$ has demonstrated that programmes targeted at improving the sexual health of young people in NI must be multifaceted and address the individual, social and economic factors involved. Schubotz et al..$^{5}$ recommended that a lower rate of teenage pregnancy and STIs could be achieved by modifying three important factors: sex education, sexual climate/attitudes and sexual health services.

The effective uptake of sexual health services by young people is influenced by various factors including their awareness and knowledge of the services that are available. The Social Exclusion Unit identified ignorance, both about contraception and sexual health services as factors contributing to Britain's high level of teenage conceptions and STI rates. ${ }^{2}$ Within NI research demonstrates that many young people are unsure about the location of local family planning clinics (FPCs) and about the services they provide. ${ }^{10-12}$ Sexual health information must be given to young people from reliable sources and in a manner that is appropriate to their needs. ${ }^{13}$

This study aimed to investigate the knowledge and utilisation of sexual health services and their associations with various sociodemographic variables amongst a sample of young people living within one health and social services Trust area in NI.

\section{Methods}

Due to the sensitive nature of the topic under investigation, an anonymous self-administered questionnaire survey was used to collect data. In order to obtain both quantitative and qualitative data the questionnaire contained both closed and open-ended questions. This article reports on the quantitative findings only.

The research team designed the questionnaire around topics generated by the relevant literature. Once formulated the instrument was pilot tested twice, initially by a sample of first year university students $(n=51)$ and then (following amendment) by final year students $(n=34)$ in a bid to check clarity and suitability for the sample of young people. As a result of the pilot study some questions were removed or rephrased.

The final version of the questionnaire was divided into five sections. The first section included questions on basic sociodemographic variables (e.g. age, gender and religious denomination). Section two attempted to establish the sexual activity of respondents as well as their use and sources of contraception. Sections three and four were aimed at assessing knowledge, awareness and utilisation of sexual health services. In the final section participants were asked to comment on the perceived barriers to accessing sexual health services and on what they thought would make an 'ideal service' for young people. This article focuses on the quantitative data obtained about young people's knowledge and sources of sexual health information.

\section{Sample}

There were 14 post-primary schools in the health and social services trust area and all were asked to participate in this research. A member of the research team made contact with each of the schools via the appropriate teacher responsible for RSE/pastoral care or in some cases the school principal. Access to pupils was granted in nine schools. Three schools refused to participate in the research whilst two schools were unable to participate due to scheduled examinations. Of these five non-responding schools, there were three grammar and two secondary schools. Three of these schools had a Roman Catholic religious ethos whilst two were predominately Protestant. All pupils invited to participate in the study completed the questionnaire and the final sample comprised 414 pupils aged between 14 and 18 years. Young men and women, secondary and grammar school students and those from both Protestant and Roman Catholic religious denominations were represented in the final sample.

A member of the research team distributed the questionnaires. In the majority of cases questionnaires were distributed and completed during a scheduled form class, although on a few occasions a member of the teaching staff arranged specific group sessions to aid questionnaire distribution. Teachers were not present during questionnaire distribution although all students completed the questions under examination conditions. Completed questionnaires were placed in a closed envelope and were collected by the researcher at the end of the session.

All questionnaires were coded and analysed using the SPSS statistical package (SPSS Inc., Chicago, IL, USA). Chi-square statistical tests were performed in order to test for associations between categorical variables.

\section{Ethical approval}

Ethical approval to carry out the study was obtained from the University of Ulster's Research Ethical Committee. A covering letter accompanied each questionnaire and this was used to inform participants about the purpose of the research and their right to refuse to participate. Pupils and schools were assured of confidentiality.

\section{Results}

\section{Profile of the sample}

A total of 414 pupils completed the questionnaire, 196 $(47.3 \%)$ young men and $218(52.7 \%)$ young women. Respondents ranged in age from 14 to 18 years with the mean age of the sample being 16.1 years $(\mathrm{SD}=0.996)$. More than half $(59.2 \%)$ of the respondents reported belonging to a Protestant religious denomination with $25.5 \%$ from a Roman Catholic background.

\section{Sexual activity}

Almost half $(46.4 \%)$ of the respondents reported experiencing sexual intercourse. Of these respondents reporting to be sexually active, $48.5 \%$ were below the legal age of consent (17 years of age in NI). A similar percentage of young men $(46.9 \%)$ and young women $(45.9 \%)$ reported engaging in sexual activity. Grammar school pupils reported lower levels of sexual activity (23.6\%) than pupils from secondary schools $(52.6 \%)\left(\chi^{2}=23.66, \mathrm{df}=1\right.$, $p<0.001)$ whilst respondents of a Roman Catholic religious 
Table 1 Demographic characteristics of respondents stratified by gender

\begin{tabular}{|c|c|c|c|c|c|c|}
\hline \multirow[t]{3}{*}{ Demographic characteristic } & \multicolumn{4}{|c|}{ Gender } & \multirow{2}{*}{\multicolumn{2}{|c|}{ Total }} \\
\hline & \multicolumn{2}{|c|}{ Male } & \multicolumn{2}{|c|}{ Female } & & \\
\hline & $n$ & $\%$ & $n$ & $\%$ & $n$ & $\%$ \\
\hline \multicolumn{7}{|l|}{ Age (years) } \\
\hline 14 & 5 & 2.6 & 6 & 2.8 & 11 & 2.7 \\
\hline 15 & 52 & 26.5 & 69 & 31.7 & 121 & 29.2 \\
\hline 16 & 76 & 38.8 & 60 & 27.5 & 136 & 32.9 \\
\hline 17 & 50 & 25.5 & 62 & 28.4 & 112 & 27.1 \\
\hline 18 & 13 & 6.6 & 21 & 9.6 & 34 & 8.2 \\
\hline Total & 196 & 100.0 & 218 & 100.0 & 414 & 100.0 \\
\hline \multicolumn{7}{|l|}{ Religious denomination } \\
\hline Protestant & 113 & 57.7 & 131 & 60.6 & 244 & 59.2 \\
\hline Roman Catholic & 44 & 22.4 & 61 & 28.2 & 105 & 25.5 \\
\hline No religious affiliation & 39 & 19.9 & 24 & 11.1 & 63 & 15.3 \\
\hline Total & 196 & 100.0 & 216 & 100.0 & 412 & 100.0 \\
\hline \multicolumn{7}{|l|}{ Type of school attended } \\
\hline Grammar & 43 & 21.9 & 46 & 21.1 & 89 & 21.5 \\
\hline Secondary & 153 & 47.1 & 172 & 52.9 & 325 & 78.5 \\
\hline Total & 196 & 47.3 & 218 & 52.7 & 414 & 100.0 \\
\hline
\end{tabular}

affiliation reported higher levels of sexual activity (54.3\%) than young people of a Protestant religious denomination $(39.3 \%)\left(\chi^{2}=6.66, \mathrm{df}=1, p=0.01\right)$.

When asked if they or their partner used some form of contraception during sexual intercourse, $68.2 \%$ reported using contraception 'all of the time'. The remaining sexually active participants failed to use contraception consistently, with $30.2 \%$ using contraception only 'some of the time' and $1.6 \%$ 'never' using contraception. Young women were more likely to use contraception 'all of the time' $(73.0 \%)$ in comparison to young men (63.0\%). Pupils attending grammar schools reported more consistent use of contraception $(76.2 \%)$ than did pupils from secondary schools $(67.3 \%)$. Young people with a Roman Catholic religious affiliation reported lower levels of contraception use $(64.9 \%)$ than did Protestant respondents $(69.8 \%)$. None of these differences reported in the use of contraception between type of school, gender or religious denomination achieved statistical significance.

Condoms were the most popular method of contraception and had been used by $92.2 \%$ of sexually active respondents $(97.8 \%$ young men and $86.0 \%$ young women). Only $21.4 \%$ of young women and/or the female partners of young men used the contraceptive pill.

The majority $(87.4 \%)$ of sexually active pupils had heard of the 'morning-after pill'. A high percentage (40.8\%) of sexually active young women had used the "morningafter pill', with $37.5 \%$ of these relying on this method on more than one occasion. Young women under the legal age of consent reported similar frequency of emergency contraceptive (EC) use as those aged over 17 years. No statistical associations were observed in the use of the 'morning-after pill' with either type of school or religious denomination. Family planning clinics were the most commonly reported providers of the 'morning-after pill'.

\section{Knowledge of sexual health services}

Approximately two-thirds (62.8\%) of respondents did not know the location of their local FPC. Young women $(45.4 \%)$ and those respondents who were sexually experienced $(51.6 \%)$ were more likely to be able to locate local family planning services than young men $(28.1 \%)\left(\chi^{2}\right.$ $=13.3, \mathrm{df}=1, p<0.001)$ and those respondents who had not experienced sexual intercourse $(24.8 \%)\left(\chi^{2}=31.6, \mathrm{df}=1\right.$, $p<0.001)$. No statistical associations were found with type of school or religious denomination.
Knowledge of the various services provided by FPCs was inconsistent. Services most commonly reported by respondents were safe sex advice (84.5\%) and contraceptive advice (78.7\%). Pregnancy tests were recognised as a family planning service by $65.0 \%$ of respondents whilst the provision of EC was recognised by $60.6 \%$. Services provided by FPCs that were less frequently identified were STI screening $(48.6 \%)$ and specific services for young men (26.1\%). In general, young women were more knowledgeable about family planning services than were young men (Table 2).

\section{Sources of sexual health knowledge}

Young people were asked to identify the sources of information that had provided them with their knowledge of sexual health services. The sources that were most commonly reported were schoolteachers $(52.7 \%)$, friends

Table 2 Knowledge of services provided by family planning clinics stratified by gendera

\begin{tabular}{|c|c|c|c|c|c|c|}
\hline \multirow{3}{*}{$\begin{array}{l}\text { Knowledge of } \\
\text { services }\end{array}$} & \multicolumn{4}{|c|}{ Gender } & \multirow{2}{*}{\multicolumn{2}{|c|}{ Total }} \\
\hline & \multicolumn{2}{|c|}{ Male } & \multicolumn{2}{|c|}{ Female } & & \\
\hline & $n$ & $\%$ & $n$ & $\%$ & $n$ & $\%$ \\
\hline $\begin{array}{l}\text { Contraception } \\
\text { advice }\end{array}$ & 142 & 72.4 & 184 & 84.4 & 326 & 78.7 \\
\hline $\begin{array}{l}\text { Female } \\
\text { contraceptive } \\
\text { supplies }\end{array}$ & 92 & 46.9 & 119 & 54.6 & 211 & 51.0 \\
\hline $\begin{array}{l}\text { Safe sex } \\
\text { advice }\end{array}$ & 156 & 79.6 & 194 & 89.0 & 350 & 84.5 \\
\hline STI tests & 89 & 45.4 & 112 & 51.4 & 201 & 48.6 \\
\hline $\begin{array}{l}\text { 'Morning-after } \\
\text { pill' }\end{array}$ & 98 & 50.0 & 153 & 70.2 & 251 & 60.6 \\
\hline $\begin{array}{l}\text { Male } \\
\text { contraceptive } \\
\text { supplies }\end{array}$ & 103 & 52.6 & 124 & 56.9 & 227 & 54.8 \\
\hline $\begin{array}{l}\text { Pregnancy } \\
\text { tests }\end{array}$ & 111 & 56.6 & 158 & 72.5 & 269 & 65.0 \\
\hline $\begin{array}{l}\text { Specific services } \\
\text { for young men }\end{array}$ & 56 & 28.6 & 52 & 23.9 & 108 & 26.1 \\
\hline
\end{tabular}

aFigures do not total $100 \%$ as multiple responses were given. STI, sexually transmitted infections. 
McLaughlin et al.

Table 3 Sources of sexual health service information stratified by gendera

\begin{tabular}{|c|c|c|c|c|c|c|}
\hline \multirow{3}{*}{$\begin{array}{l}\text { Information } \\
\text { source }\end{array}$} & \multicolumn{4}{|c|}{ Gender } & \multirow{2}{*}{\multicolumn{2}{|c|}{ Total }} \\
\hline & \multicolumn{2}{|c|}{ Male } & \multicolumn{2}{|c|}{ Female } & & \\
\hline & $n$ & $\%$ & $n$ & $\%$ & $n$ & $\%$ \\
\hline Mother $r^{\star * *}$ & 56 & 28.6 & 103 & 47.2 & 159 & 38.4 \\
\hline Father ${ }^{\star * *}$ & 47 & 24.0 & 21 & 9.6 & 68 & 16.4 \\
\hline Brother/sister & 24 & 12.2 & 33 & 15.1 & 57 & 13.8 \\
\hline Television/radio & 70 & 35.7 & 81 & 37.2 & 151 & 36.5 \\
\hline $\begin{array}{l}\text { Books/ } \\
\text { magazines }\end{array}$ & 55 & 28.1 & 130 & 59.6 & 185 & 44.7 \\
\hline Doctor & 15 & 7.7 & 29 & 13.3 & 44 & 10.6 \\
\hline Nurse & 6 & 3.1 & 9 & 4.1 & 15 & 3.6 \\
\hline School nurse & 15 & 7.7 & 20 & 9.2 & 35 & 8.5 \\
\hline Youth group* & 24 & 12.2 & 14 & 6.4 & 38 & 9.2 \\
\hline $\begin{array}{l}\text { Schoolteacher/ } \\
\text { class }\end{array}$ & 101 & 51.5 & 117 & 53.7 & 218 & 52.7 \\
\hline Internet ${ }^{* \star *}$ & 26 & 13.3 & 3 & 1.4 & 29 & 7.0 \\
\hline $\begin{array}{l}\text { Girlfriend/ } \\
\text { boyfriend }\end{array}$ & 39 & 19.9 & 34 & 15.6 & 73 & 17.6 \\
\hline Friends* & 86 & 43.9 & 120 & 55.0 & 206 & 49.8 \\
\hline Helplines & 3 & 1.5 & 2 & 0.9 & 5 & 1.2 \\
\hline Agencies & 2 & 1.0 & 4 & 1.8 & 6 & 1.4 \\
\hline $\begin{array}{l}\text { Family planning } \\
\text { clinic }\end{array}$ & 11 & 5.6 & 14 & 6.4 & 25 & 6.0 \\
\hline Church & 14 & 7.1 & 7 & 3.2 & 21 & 5.1 \\
\hline
\end{tabular}

aFigures do not total $100 \%$ as multiple responses were given.

${ }^{*}$ Denotes significance at $p<0.05$

${ }^{* * *}$ Denotes significance at $p<0.001$.

$(49.8 \%)$, books/magazines $(44.7 \%)$ and television/radio $(36.5 \%)$. Over one-third (38.4\%) of respondents obtained information from their mothers. Sources least commonly reported were practice nurses $(3.6 \%)$, non-statutory agencies $(1.4 \%)$ and helplines $(1.2 \%)$. Pupils from grammar and secondary schools reported similar sources of sexual health knowledge. However, grammar school pupils were more likely to have received information from their schoolteachers $(62.9 \%)$ than those pupils attending secondary schools $(49.8 \%)\left(\chi^{2}=4.79, \mathrm{df}=1\right.$, $p=0.029$ ).

Associations were found between gender and sources of sexual health services information. Young females were more likely to have obtained their sexual health service information from their mothers in comparison to young men $\left(\chi^{2}=15.22\right.$, $\left.\mathrm{df}=1, p<0.001\right)$. Compared to young men, women were more likely to access information from books and magazines $\left(\chi^{2}=41.62, \mathrm{df}=1, p<0.001\right)$ and to have obtained information from their friends $\left(\chi^{2}=5.15, \mathrm{df}\right.$ $=1, p=0.023)$. In contrast, young men were more likely to have accessed information from their fathers $\left(\chi^{2}=15.48\right.$, $\mathrm{df}=1, p<0.001)$ and from the Internet $\left(\chi^{2}=22.40, \mathrm{df}=1\right.$, $p<0.001)$ compared to young women (Table 3 ).

Chi-square analysis also revealed significant associations between religious denomination and sources of sexual health service information. A significantly higher percentage of Roman Catholic respondents indicated that they received sexual health service information from their friends $(64.8 \%)\left(\chi^{2}=12.86, \mathrm{df}=2, p=0.002\right)$, books/magazines $(51.4 \%)\left(\chi^{2}=6.19, \mathrm{df}=2, p=0.045\right)$ and television/radio $(47.6 \%)\left(\chi^{2}=7.56, \mathrm{df}=2, p=0.023\right)$ than pupils from a Protestant religious background $(43.9 \%$, $44.7 \%$ and $33.6 \%$, respectively). However, in comparison to Protestant respondents and young people of no religious affiliation, Catholic respondents were less likely to receive information from a school nurse $\left(\chi^{2}=6.89\right.$, df $=2, p=$
0.032). Whilst the church was not as commonly reported as other sources of sexual health information, a higher proportion $(7.4 \%)$ of young people from a Protestant religious background reported receiving information from this source compared to Roman Catholic students.

\section{Utilisation of sexual health services}

Only $9.7 \%$ of respondents had availed themselves of the sexual health services in their area. In fact, only $20.7 \%$ of sexually active respondents had sought any sexual health information or advice from statutory sources. Similar percentages of pupils had contacted their general practitioner (GP) and FPC and only one pupil had been in contact with a genitourinary medicine clinic. Significant associations were observed with regard to utilisation of sexual health services and gender. Young women were three times more likely (14.2\%) to have used sexual health services than young men $(4.6 \%)\left(\chi^{2}=10.96, \mathrm{df}=1, p=\right.$ $0.01)$. There were no statistical associations between use of sexual health services and either type of school or religious denomination.

\section{Discussion}

The issue of sexual health within NI is a major concern given the high incidence of teenage pregnancy and increasing rates of STIs. ${ }^{14}$ Despite these figures there is a particular dearth of research conducted on this topic due to the social and cultural climate surrounding sexual health within NI. Given these factors, achieving the relevant permission and access to research the sexual behaviours of young people was an achievement in itself. Only five postprimary schools within the Trust area did not participate in this study, resulting in a final sample that was representative in terms of religious perspective. The religious breakdown is comparable with the latest Census

Table 4 Sources of sexual health service information according to religious affiliationa

\begin{tabular}{|c|c|c|c|c|c|c|}
\hline \multirow{3}{*}{$\begin{array}{l}\text { Information } \\
\text { source }\end{array}$} & \multicolumn{6}{|c|}{ Religious affiliation } \\
\hline & \multicolumn{2}{|c|}{ Protestant } & \multicolumn{2}{|c|}{$\begin{array}{l}\text { Roman } \\
\text { Catholic }\end{array}$} & \multicolumn{2}{|c|}{ None } \\
\hline & $n$ & $\%$ & $n$ & $\%$ & $n$ & $\%$ \\
\hline Mother & 100 & 41.0 & 32 & 30.5 & 27 & 42.9 \\
\hline Father & 40 & 16.4 & 13 & 12.4 & 15 & 23.8 \\
\hline Brother/sister & 33 & 13.5 & 18 & 17.1 & 6 & 9.5 \\
\hline Television/radio* & 82 & 33.6 & 50 & 47.6 & 19 & 30.2 \\
\hline $\begin{array}{l}\text { Books/ } \\
\text { magazines* }\end{array}$ & 109 & 44.7 & 54 & 51.4 & 20 & 31.7 \\
\hline Doctor & 24 & 9.8 & 14 & 13.3 & 24 & 9.8 \\
\hline Nurse & 7 & 2.9 & 7 & 6.7 & 1 & 1.6 \\
\hline School nurse* & 27 & 11.1 & 3 & 2.9 & 4 & 6.3 \\
\hline Youth group & 22 & 9.0 & 10 & 9.5 & 6 & 9.5 \\
\hline $\begin{array}{l}\text { Schoolteacher/ } \\
\text { class }\end{array}$ & 135 & 55.3 & 49 & 46.7 & 32 & 50.8 \\
\hline Internet & 18 & 7.4 & 6 & 5.7 & 5 & 7.9 \\
\hline $\begin{array}{l}\text { Girlfriend/ } \\
\text { boyfriend }\end{array}$ & 36 & 14.8 & 24 & 22.9 & 13 & 20.6 \\
\hline Friends** & 107 & 43.9 & 68 & 64.8 & 31 & 49.2 \\
\hline Helplines & 2 & 0.8 & 2 & 1.9 & 1 & 1.6 \\
\hline Agencies & 2 & 0.8 & 3 & 2.9 & 1 & 1.6 \\
\hline $\begin{array}{l}\text { Family planning } \\
\text { clinic }\end{array}$ & 14 & 5.7 & 7 & 6.7 & 4 & 6.3 \\
\hline Church & 18 & 7.4 & 1 & 1.0 & 2 & 3.2 \\
\hline
\end{tabular}

aFigures do total $100 \%$ as multiple responses were given. *Denotes significance at $p<0.05$.

**Denotes significance at $p<0.01$ 
figures for the locality which showed that $53.3 \%$ of residents were Protestant, 25.9\% Roman Catholic and $13.8 \%$ claimed to have no religious affiliation. ${ }^{15}$ The present study has also a representative sample of both male and female participants. Previous research conducted about sexual health services has primarily focused on females. This bias reflected the fact that traditionally the majority of sexual health service clients were female. As the use of sexual health services by males has substantially increased $^{16}$ it was considered important to include the views of young men in this study. This study was limited, however, by the fact that the schools themselves identified the particular year/class groups to participate, which resulted in an over-representation of older pupils from grammar schools and from a Roman Catholic background. Nonetheless, given the age range of the participants in the study it is likely that all respondents would have already had access to formal sexual health education.

Approximately half the young people in this study were sexually active, which is similar to the results obtained from the largest study conducted nationally in NI on the sexual attitudes and lifestyles of young people. ${ }^{5}$ In the aforementioned study 5 researchers reported a slightly higher figure of $56 \%$ but the mean age of their sample (17.3 years) was higher than that obtained in the present survey. It has sometimes been assumed that the sexual behaviour of young people in NI may differ from that of young people living in other parts of the UK given the differing sexual health policies that exist. However, the results obtained from the present study are similar to UK studies 17,18 and would suggest that such claims are not justified.

Despite such a high level of sexual activity, particularly amongst those below the legal age of consent, approximately one-third of respondents were not taking contraceptive precautions all of the time. Whilst the results are not directly comparable, the present figures would appear to be higher than the results reported by both NISRA $^{9}$ and Schubotz et al. ${ }^{5}$, although their figures referred to contraceptive use at first intercourse. Similarly, results reported from the NATSAL survey ${ }^{17}$ regarding contraceptive use would suggest that contraceptive use in NI is lower than that reported in the rest of the UK. It is therefore not surprising that these respondents reported considerable use of EC with $40.8 \%$ of sexually active respondents reporting using the 'morning-after pill'. In fact, over one-third of these respondents had relied on this secondary source on more than one occasion. This frequent repeat use of EC has been shown in other UK studies ${ }^{19}$ and in fact 'over the counter' sources can often lead to an underestimation of its use. ${ }^{19}$ Whilst chemist shops provide an accessible and convenient method of obtaining EC, particularly for young people, they should be encouraged to seek advice from their GP or local FPC where they can discuss their general sexual health and future contraception needs. Repeat use of EC is not in itself considered dangerous but it is not suitable as a regular method of contraception. ${ }^{19}$

The use of sexual health services reported in the present study was also extremely low given the high level of sexual activity. Consistent with other studies 20,21 , young women in the present study were more likely to use the services than young men, possibly because of a greater concern over pregnancy. ${ }^{22}$ In fact, within NI, the working group on teenage pregnancy highlighted the need for sexual health services to be tailored not only for young people but, in particular, for young men. This view has been echoed by other recent findings and Pearson ${ }^{16}$ concluded that effective promotion campaigns (designed with the help of young men) combined with accessible services could increase service use among young men. Whilst there was a clear gender difference in service use, no other differences were observed in this study. Religious denomination did not affect service use among this group of young people, a finding consistent with young people in other parts of the $\mathrm{UK} .22$

It is generally accepted that sex education forms a major part of health education. In NI, sex education within the school environment has now been given prominence with the development of RSE in 2001. Prior to RSE, policies on sex education were controlled by the board of governors in individual schools and were thus "taught in a sensitive manner in harmony with the ethos of the school or college and in conformity with the moral and religious principles held by parents and school management authorities". 23 Whilst the introduction of RSE guidelines has led to improvements, there still appears no uniform pattern in the provision of sex education in schools, resulting in inequalities in sexual health education. For example, some schools offer wellplanned sex education programmes, others provide occasional one-off sessions, whilst in some schools there is no formal sex education. In the present study inequalities were reported with regard to the provision of information through the education system and the national survey conducted by Schubotz et al.5 also revealed inconsistencies in sex education provision. Whilst this study did not investigate the implementation of the sex education policies within each individual school, the findings reported by the young people would suggest that grammar school teachers provide more information on sexual health. Given that grammar school pupils in NI are usually of a higher educational ability, the fact that they reported receiving more sex education in schools than young people attending secondary schools may increase further the inequalities that exist in the provision of sexual health information. Whilst educational ability may partly explain the variation in contraceptive use, the slightly higher age range of grammar school pupils in this study may also confound this result as other studies have shown that contraceptive use increases with increasing age. ${ }^{24}$

Findings from this study showed that young Catholic respondents were less likely to obtain sexual health service advice from their schoolteachers or school nurse in comparison to Protestant respondents. In fact, these Catholic respondents were more likely to receive information on sexual health from their friends, books/magazines and television/radio than from the school education system. Whilst peer support during adolescent years is crucial for personal and social development, young people should have access to a more formal source of sex education. Informal peer group discussions should not be relied upon to provide accurate or essential information. Notwithstanding the negative aspect of this 'friendly advice', the high number of these young people who discuss sexual health issues with their friends supports the view that formal peer group education could be particularly good at promoting sexual health. 25

It is claimed that one advantage of peer-led programmes over traditional teacher-led methods is that those of a similar age can convey sensitive information in a more appropriate and appealing way. ${ }^{25}$ Whilst the evidence base for peer-led interventions in health education remains unclear, ${ }^{25}$ the high number of young people in this study who relied on their peers for sexual health advice suggests the potential effectiveness of implementing a more 'formal' peer group approach and warrants further investigation. 
McLaughlin et al.

Ideally sex education needs to be tackled from a number of sources and input provided by parents and health professionals should also be a factor. The traditional role of the mother and father in educating their daughters and sons, respectively, was still apparent in this population of young people, albeit in a limited capacity. One-quarter of male students reported receiving sexual health information from their fathers compared to less than $19 \%$ of female students. In contrast, almost half the female students received sexual health information from their mothers compared to only $28.6 \%$ of males. It is possible that parents feel ill equipped with the necessary skills and confidence to explain sexual health issues to their children. In fact, the Family Planning Association for NI reported that parents failed to provide sex education because of feelings of embarrassment and the belief that it was being taught in school. ${ }^{26,27}$ In fact, $98 \%$ of parents in NI wanted schools to play a role in teaching sex education to young people 28 and consequently many parents had not discussed sexual issues with their children. The reliance by parents on the school sex education programme and the inconsistency of that provision will only increase the inequalities that exist in the level of sexual health knowledge.

Modern media are now part of everyday life and thus their role in providing sexual health information should not be underestimated. Increasingly, the public engage in health-seeking behaviour via the Internet, ${ }^{29}$ and this source of information in particular is seen as a useful vehicle for young people to gather information on sensitive topics such as sexual health. ${ }^{30}$ Whilst the findings from the present study indicate limited use of the Internet, extant research has shown that NI is trailing the rest of Europe and America in its use of the Internet. ${ }^{31}$ Young people in NI may have limited access to sexual health information on the Internet due to school or parental 'blocks' on specific sites. However, it is also possible that the reported Internet use in this study was low because sites providing local information about sexual health services were not available.

Adolescence is a critical life stage when lifestyle choices are established, and sexual health behaviour at this stage can impact throughout life. However, providing crucial information about sexual health to young people poses many challenges to health professionals, educators and parents because of the sensitive nature of the issue and the difficulties young people can face accessing information. The World Health Organization believes that education for health is a fundamental right of every child, ${ }^{32}$ yet the findings from the present study have shown that inequalities exist in the provision of sexual health information.

Schools remain inconsistent in their provision of sexual health information and yet parents often solely rely on this source to provide their children with information relevant to the promotion of sexual health. Inequalities in the sources of information were particularly evident in the differences shown to exist between Catholic and Protestant respondents. It is essential that schools standardise their interpretation of the RSE guidelines and develop new methods of implementing these guidelines so that young people can receive the same messages. The provision of accurate and comprehensive information has considerable potential to enhance sexual health status but this can only be achieved on a national level if information is consistent and available to all.

\section{Statements on funding and competing interests}

Funding Funding for this project was provided by Causeway Health and Social Services Trust.

Competing interests None identified.
References

1 The United Nations Children's Fund (UNICEF). A League Table of Teenage Births in Rich Nations. (Innocenti Report Card, Issue No. 3, July 2001). Florence, Italy: UNICEF Innocenti Research Centre, 2001. http://www.unicef-icdc.org/ publications/pdf/repcard3e.pdf [Accessed 12 December 2005].

2 Social Exclusion Unit. Teenage Pregnancy Report. London, UK: Stationary Office, 1999.

3 Weyman A. Promoting sexual health to young people: preventing teenage pregnancy and sexually transmitted infections. Journal of the Royal Society for the Promotion of Health 2003; 121: 6-7.

4 Eurydice at NFER. Overview of the Education System in England, Wales and Northern Ireland. http://www.nfer.ac.uk/ eurydice/briefingsuk/verview-of-education-system-in-englandwales-and-northern-ireland.cfm [Accessed 12 December 2005].

5 Schubotz D, Simpson A, Rolston B. Towards Better Sexual Health: A Survey of Sexual Attitudes and Lifestyles of Young People in Northern Ireland. Belfast, Northern Ireland: The Family Planning Association, 2002.

6 Council for the Curriculum, Examinations and Assessment (CCEA). Relationships and Sexuality Education: Guidance for Post Primary Schools. Belfast, Northern Ireland: Northern Ireland CCEA, 2001.

7 Teenage pregnancy rates continue to fall (Press release). The Department of Health, Social Services and Public Safety. http://www.nics.gov.uk/press/hss/050216y-hss.htm [Accessed 22 April 2005]

8 Health Protection Agency (HPA). Diagnoses of Selected STIs by Region, Age and Sex Seen at GUM Clinics: National Level Summary Tables, 1995-2003. London, UK: HPA, 2004.

9 Northern Ireland Statistics and Research Agency (NISRA). Northern Ireland Health and Wellbeing Survey 2001. Belfast, Northern Ireland: Department of Health, Social Services and Public Safety, 2001.

10 Finlay A, Shaw N, Whittington D. Reproductive Behaviour in the Western Health and Social Services Board Area. A study carried out by the Centre for Health and Social Research Unit, University of Ulster, 1995

11 Northern Health and Social Services Board (NHSSB). Young People and Homelessness in the NHSSB Area. Northern Health and Social Services Board: Simon Community, 1997. http://www.simoncommunity.org/filestore/documents/Archived research.doc [Accessed 22 April 2005].

12 Casson K, Fleming P. Sexual Health and Service Development in the Coleraine Area. A report to the Northern Health and Social Services Board, 2002.

13 Aggleton P, Chalmers H, Daniel S, Warwich I. Promoting Young People's Sexual Health: A Compendium of Family Planning Service Provision for Young People. London, UK: Health Education Authority, 1996.

14 McCarthy M. Teenage pregnancy in Northern Ireland. Promoting Health 2000; 11: 15-18.

15 Northern Ireland Statistics and Research Agency (NISRA). NI Census Analyser. http://www.nicensus2001.gov.uk/nica/ analyser/analyser?topicld=1\&tableld=\&tableName=Religion\&s electedTopicld $=\&$ aggregated $=$ false $\&$ subject $=\&$ tableNumber $=\&$ selectedLevelld $=\&$ postcode $=\&$ areaText $=\&$ RADIOLAYER $=\&$ act ionName $=$ view -results $\&$ clearAreas $=\&$ stateData $1=\&$ state Data2=\&st [Accessed 12 December 2005].

16 Pearson S. Men's use of sexual health services. J Fam Plann Reprod Health Care 2003; 29(4): 190-194.

17 Wellings K, Nanchahal K, Macdowall W, McManus S, Erens B, Mercer $\mathrm{CH}$, et al. Sexual behaviour in Britain: early heterosexual experience. Lancet 2001; 358: 1843-1850.

18 Johnston AM, Mercer CH, Erens B, Copas AJ, McManus S, Wellings $\mathrm{K}$, et al. Sexual behaviour in Britain: partnerships, practices, and HIV risk behaviours. Lancet 2001; 358: 1835-1842.

19 Roizen J, Garside R, Barnett L. Repeat use of emergency contraception: how frequent is it? J Fam Plann Reprod Health Care 2001; 27: 197-202.

20 Nwokolo N, McOwan A, Hennerby G, Chislett L, Mandalia S. Young people's views on provision of sexual health services. Sex Transm Infect 2002; 78: 343-346.

21 Porter L, Leighton K. Use of reproductive health services among young men. J Adolesc Health 2000; 27: 186-194.

22 Parkes A, Wight D, Henderson M. Teenagers' use of sexual health services: perceived need, knowledge and ability to access. J Fam Plann Reprod Health Care 2004: 30: 217-224.

23 Department of Education for Northern Ireland (DENI). Sex Education. Circular No. 1987/45. Belfast, Northern Ireland: DENI, 1987.

24 Lo SV, Kaul S, Kaul R, Cooling S, Calvert JP. Teenage 
pregnancy - contraceptive use and non-use. Br J Fam Plann 1994; 20: 79-83.

25 Stephenson JM, Strange V, Forrest S, Oakley A, Copas A, Allen $\mathrm{E}$, et al for the RIPPLE study team. Pupil-led sex education in England (RIPPLE study): cluster-randomised intervention trial. Lancet 2004; 364: 338-346.

26 Department of Health. Involving Young People in Peer Education: A Guide to Establishing Sex and Relationships Peer Education Projects. London, UK: Department of Health, Teenage Pregnancy Unit, 2002.

27 Health Promotion Agency for Northern Ireland (HPANI). Parental Attitudes Towards Sex Education in Northern Ireland. Exploratory Research Prepared for the Health Promotion Agency for Northern Ireland. Belfast, Northern Ireland: HPANI, 1992.

28 Health Promotion Agency for Northern Ireland (HPANI). Sex
Education in Northern Ireland: Views from Parents and Schools. Belfast, Northern Ireland: HPANI, 1996.

29 Cline RJW, Haynes KM. Consumer health information on the Internet: the state of the art. Health Education Research: Theory and Practice 2001; 16: 671-692.

30 Goold PC, Ward M, Carlin EM. Can the Internet be used to improve sexual health awareness in web-wise young people. $J$ Fam Plann Reprod Health Care 2003; 29(1): 28-30.

31 Gray AM, Whittington D, Thompson K. Information, participation and trust in health care. In: Lloyd K, Devine P, Gray AM, Heenan D (eds), Social Attitudes in Northern Ireland: The Ninth Report. London, UK: Pluto Press, 2004.

32 World Health Organization (WHO). Adolescent Friendly Health Services - An Agenda for Change. Geneva, Switzerland: WHO, 2002.

VIEW FROM PRIMARY CARE

\section{"Nine out of ten patients survived"}

\section{Nicholl}

So it's finally happened: the NHS is being allowed to enter the world of fluff, glamour and backstabbing, or advertising as it's known by most. This licence to kill off the competition, literally, may well be shrouded in regulatory codes to give it authenticity but this of course is advertising in its best form - dressing up something evil and destructive to make it look real and above board.

If I sound suspicious of this idea then it's because maybe I am. The pharmaceutical industry lavished GPs with expensive gifts, trips, food and drinks for years. But they stamped that out, didn't they? Oh, how those educational meetings at five-star hotels in foreign cities, supping Bollinger with the reps are missed. I don't know who felt it the most. Those who had come to rely on conferences providing family holidays or those heading for general practice who saw the freebie rug pulled out from under them before they'd had the chance to enjoy the benefits of the combination TV and video used to screen a company's latest educational advert and conveniently forgotten by the drug rep afterwards.

But now once again the NHS is to re-invent the wheel, as it always does. Very soon it would appear that NHS providers will be able to promote their services, and indeed compare themselves with other providers. What fun GPs are going to have with the new 'Trust reps' who will take the place of 'drug reps'. In bygone days, to save time I know some GPs would schedule two competing pharmaceutical reps in to see them at the same time, and then watch them play 'pharma tennis' as one tried to convince the other that their product was better. It was easy really; if the reps wanted an audience with the GP they had to play ball. It should be fun watching the Trusts competing in this way: "... well, six of your sterilisations fell pregnant last year". "At least all of ours left the hospital."

Then, of course, there will be the inevitable return to the lavish evening meetings at splendid hotels and restaurants. After all, the guidance does say that costs of hotels, food, and so on, should not exceed the level recipients would normally choose when paying for themselves. A GP's host may no longer be the pharmaceutical industry; it's now the new GMS contract so "as a GP I can honestly say [cue

J Fam Plann Reprod Health Care 2007; 33(2): 105

Fluffenstab, UK

C Nicholl, MRCGP, General Practitioner resting fingers against cheek and caring smile to complete empathic look] that my standards remain as high as ever".

So they'll be trying to get our business, and the patients' business too. Get ready for irritating and tranquillitydestroying cold calls and text messages informing us how we've made it into the last ten for a dream operation of our choice, that the thousandth caller will win a state-of-the-art air-conditioned therapy suite where coils, implants and 'depos' can be provided faster and quicker than ever before, or that if we order now we'll receive a free plasma screen so patients can watch their procedure in high definition that 'puts you where the action is'. Hell knows what will happen if they are invited to 'press the red button'. A link to some medical negligence claim company no doubt.

At the moment the focus is on hospital Trusts promoting their services but primary care is included in this little wheeze. I guess it won't be long before we see a fleet of new Minis with smart paint jobs advertising their driver's practice. Mine would probably be along the lines of: "At the Open Heart Surgery you'll be welcomed by open minds and arms". Cheesy I know, but what adverts aren't?

TV adverts will soon follow. Bearing in mind the current litigation climate it would be wise to place them after those aforementioned and irritating medical negligence claim adverts. This way the public can be told: "There's never been a successful claim against our practice - so if you want great health care come and join us, but if you're after a fast buck we'll refer you for a colonoscopy".

I've already seen potential practice adverts for our local newspapers. Not that I'm interested of course, but it's important to know what our competition may be doing. One such mock-up informed its readers that: "Our practice has more fit and healthy patients then any other practice around". Then with a group photo of the practice team, who looked somewhat high, the advert announced: "How do we achieve this? Well, because we care, and take great care of our patients who are like family to us - and after all, you're worth it". I enjoyed the irony, as I don't like to see my family too often either. Of course, the subliminal message of this advert would encourage the fit and well to join the practice's list whilst ensuring that those with the slightest blemish of imperfection felt they couldn't. I had to concede that the strategy was clever, and had a certain appeal.

But I can feel myself being sucked in. I'm still really suspicious of this idea or am I? All that's gone before may simply be the bluff of great advertising! 